\title{
O USO DE MATERIAL CONCRETO NO ENSINO E APRENDIZAGEM DA MATEMÁTICA
}

\author{
KARINA MARIA da FONSECA LUCIANO ${ }^{1}$
}

\begin{abstract}
O presente trabalho é dedicado ao estudo das possibilidades que o uso de objetos concretos proporciona ao ensino de conceitos básicos da geometria. Essa pesquisa teve como principal foco a busca por um aprendizado dos conceitos geométricos através da utilização de materiais concretos diversificados, que estão fundamentados teoricamente na revisão de literatura. Sabendo-se que a geometria está presente nas mais diferentes situações do dia-a-dia, esse conteúdo está sendo relegado no ensino-aprendizagem da matemática. Por isso, esse trabalho teve como objetivo a realização de uma pesquisa de campo para mostrar que é necessário que os alunos adquiram, entendam e compreendam os principais conceitos geométricos presentes no currículo matemático. Para que isso ocorresse, mostrou-se que a utilização de material concreto variado, como, por exemplo, isopor, palitos, canudos, botão de camisa e arame, podem ser utilizados como recursos didático-pedagógicos em sala de aula para o ensino de geometria.
\end{abstract}

\section{INTRODUÇÃO}

A Matemática, a ideia do infinito, das tarefas infinitas, é como uma torre babilônica, que apesar de seu inacabamento, permanece uma tarefa cheia de sentido, aberta ao infinito; este infinito tem por correlato o homem novo, de metas infinitas

\section{Edmund Husserl}

O método tradicional utilizado na maioria das salas de aula de matemática não permite aos alunos tempo suficiente para que eles compreendam plenamente os conceitos básicos da matemática. Diante dessa perspectiva, uma maneira de reforçar a compreensão dos alunos em relação aos conteúdos matemáticos é a utilização de materiais concretos nas atividades curriculares propostas em sala de aula. Dessa maneira, alguns estudos mostram a importância do uso de material concreto em todos os níveis de ensino. Por

PALAVRAS-CHAVE: Aprendizagem, Geometria, Material Concreto

${ }^{1}$ Mestranda em Engenharia e Gestão de Processos e Sistemas, Instituto de Educação Tecnológica(Ietec) Professora de Cálculo Diferencial e Integral na Faenge-Uemg, Professora de Cálculo Diferencial e Integral, Geometria Analítica e Álgebra Linear no Instituto Ensinar do Brasil 
exemplo, Fiorentini e Miorim (1990) afirmam que Pestalozzi (1746-1827) acreditava que uma educação seria considerada genuinamente educativa se a sua ação pedagógica enfatizasse as atividades realizadas pelos alunos, como, por exemplo, a manipulação de objetos concretos. Nesse sentido, Castelnuovo (1970) argumenta que as descrições devem preceder as definições; e consequentemente, o conhecimento matemático é construído através da experiência direta com as operações sobre esses objetos. Piaget (1973) e Dienes (1967) desenvolveram argumentos favoráveis para a utilização de materiais concretos no ensino-aprendizagem da geometria. Piaget (1973), por exemplo, estudou os estágios de desenvolvimento cognitivo de crianças, o que, segundo ele, ocorre através de ações que são executadas em resposta ao ambiente através da manipulação de objetos concretos.

De acordo com Dantas e Manoel (2005), as atividades experimentais realizadas com a utilização de materiais concretos podem auxiliar os alunos a transformarem o conhecimento declarativo em processual. Esse processo é denominado de procedimentalização. Chie e Glaser (1980) afirmam que o conhecimento declarativo refere-se à informação factual, imutável e verbalizada. Esse conhecimento está relacionado com as estruturas de conhecimento que podem ser representadas através de uma rede de conceitos com as suas relações e também com a capacidade de associação entre esses conceitos. Nesse sentido, o conhecimento declarativo está relacionado com o saber o que fazer. Por outro lado, de acordo com Chie e Glaser (1980), o conhecimento processual resiste à descrição verbal e não pode ser controlado, pois esse conhecimento está relacionado com o saber como fazer. Assim, o conhecimento processual é mais complexo do que o declarativo, pois está relacionado com a ação motora em si ao utilizar os processos cognitivos necessários para a efetivação dessa ação (CHIE; GLASER, 1980).

Assim, entende-se que as atividades com materiais concretos sejam essenciais para a constituição de um ensino-aprendizagem significativo e atraente, pois esses materiais auxiliam os alunos na construção do conhecimento processual. Por exemplo, os professores trabalham com o conhecimento declarativo quando explicam aos alunos como os triângulos são classificados quanto aos seus lados através da exemplificação das suas propriedades e conceitos. Em seguida, o conhecimento processual é ativado quando os alunos transferem para o papel, de maneira lúdica, esse aprendizado. Então, os alunos procedimentalizam o conhecimento declarativo ao desenhar os triângulos e classificá-los quanto aos seus lados com a utilização de materiais concretos diversificados. De acordo 
com Piaget (1973), com a devida orientação, os alunos aprendem geometria de maneira eficiente, pois durante esse processo eles retomam os conteúdos estudados anteriormente.

Diante desse contexto, ao iniciar o estágio em uma escola estadual da cidade de João Monlevade, no Estado de Minas Gerais, a autora da pesquisa observou que, de acordo com o estabelecido por Lorenzato e Vila (1993), as aulas de geometria eram sempre ministradas ao final do ano letivo. Uma das hipóteses para essa ocorrência é que isso ocorra com muita frequência porque o conteúdo dessa disciplina encontra-se no final da maioria dos livros didáticos. Outro motivo que pode estar relacionado com o abandono do ensino da geometria nas escolas é que alguns professores evitam ministrar esse conteúdo matemático por não dominarem a maioria dos conceitos geométricos (PEREZ, 1995) ou, também, pela falta de tempo para preparar aulas diferenciadas.

Assim, nesse artigo, pretendeu-se investigar um modelo pedagógico de ensino da geometria que funcione como um continuum que se movimenta do concreto ao abstrato e vice-versa. Esse modelo pedagógico visa auxiliar alunos a construírem os conceitos matemáticos através de experiências com atividades que utilizam materiais concretos (BRASIL, 1997). Então, de acordo com essa abordagem, os professores adquirem um novo papel no ensino-aprendizagem da matemática, no qual eles elaboram atividades que envolvam experiências concretas que tenham significado para os alunos (AUSUBEL, 1982). Dessa maneira, os professores podem auxiliar os alunos a realizarem a transição do conhecimento declarativo para o processual, ou seja, a procedimentalização (DANTAS; MANOEL, 2005) através de implantação de uma didática flexível que facilite a aquisição do conhecimento geométrico.

O principal objetivo da presente pesquisa foi descobrir, juntamente com os alunos, a importância da utilização do material concreto no estudo dos conceitos geométricos como mediador na construção do conhecimento matemático; primeiramente, de maneira prática e, em seguida, praticando a generalização dos conteúdos geométricos que foram aprendidos. Nesse sentido, Borges (1998) afirma que é imprescindível que os professores se encontrem continuamente em estado de renovação, atualizando-se em técnicas de aprendizagem para que seus alunos possam aprender com eficiência através de um ensino-aprendizagem da matemática significativo e contextualizado.

Contudo, a preocupação com um ensino-aprendizagem de geometria, que seja significativo, deve ser uma preocupação contínua de todos os envolvidos no processo educacional, como, por exemplo, os alunos, os professores, os pais e a direção escolar. Enfim, essa preocupação exige o envolvimento de toda a comunidade escolar no processo 
educativo, para que o ensino-aprendizagem da geometria possa promover, nos alunos, dentre outras habilidades, a autonomia e a reflexão, preparando-os para viverem em uma sociedade complexa e globalizada. Nesse sentido, Pais (2006) afirma que os professores devem elaborar atividades que favoreçam o desenvolvimento da criatividade dos alunos através da utilização do material concreto como um recurso que tende a contribuir para a aquisição de conceitos matemáticos e geométricos, que auxiliem os alunos na resolução de problemas que são enfrentados na escola e no cotidiano.

\section{FUNDAMENTAÇÃO TEÓRICA}

De acordo com Fiorentini e Miorim (1990), no século XVI, a aprendizagem matemática dos alunos era considerada passiva, pois somente as memorizações de regras, fórmulas e conceitos matemáticos eram valorizados. Nesse modelo educacional, os professores desempenhavam o papel de transmissores e expositores de um conhecimento geométrico pronto e acabado. Os poucos professores que utilizavam o material concreto, o faziam de uma maneira puramente demonstrativa, servindo, portanto, como uma maneira de auxiliar a exposição, a visualização e a memorização dos conteúdos geométricos propostos aos alunos.

Porém, durante o século XVIII, começou-se a considerar a educação como sendo parte do processo natural do desenvolvimento das crianças. Nesse aspecto, Fiorentini e Miorim (1990) comentam que surgiu uma nova compreensão de educação, que aparece juntamente com as propostas de Pestalozzi, que almejava um processo instrucional verdadeiramente educativo, que decorresse da atividade dos alunos. Essas atividades deveriam envolver canto, desenho, modelagem, jogos, excursões ao ar livre, manipulação de objetos concretos e tarefas, nas quais as descrições deveriam preceder as definições. Dessa maneira, o conceito matemático seria adquirido da experiência direta sobre as operações (CASTELNUOVO apud FIORENTINI; MIORIM, 1990).

De acordo com Fiorentini e Miorim (1990), Maria Montessori (1870-1952) e Decroly (1871-1932), movidos pelas teorias de Pestalozzi, buscaram desenvolver uma didática distinta e ativa para o ensino-aprendizagem da matemática. Então, no início do século XX, após experimentos com crianças, a médica e educadora italiana Montessori utilizou diversos materiais manipulativos designados para auxiliar o ensinoaprendizagem da matemática. Esses materiais possuíam um forte apelo à percepção visual 
e tátil das crianças. Azevedo (1979) apud Fiorentini e Miorim (1990, p. 4) afirma que Montessori acreditava não haver aprendizagem sem ação, pois "nada deve ser dado à criança, no campo da matemática, sem primeiro apresentar-se a ela uma situação concreta que a leve a agir, a pensar, a experimentar, a descobrir, e daí, a mergulhar na abstração".

Castelnuovo (1970) apud Fiorentini e Miorim (1990) também argumenta que a teoria piagetiana mostra o conceito fundamental da ação, tornando-a reflexiva. Porém, para que isso ocorra satisfatoriamente, existe a necessidade de que:

(...) o interesse da criança seja atraído pelo objeto material em si ou pelo ente matemático, senão pelas operações sobre o objeto e seus entes. Operações que, naturalmente, serão primeiro de caráter manipulativo para depois interiorizar-se e posteriormente passar do concreto ao abstrato. Recorrer à ação, diz Piaget, não conduz de todo a um simples empirismo, ao contrário, prepara a dedução formal ulterior, desde que se tenha presente que a ação, bem conduzida, pode ser operatória, e que a formalização mais adiantada o é também (CASTELNUOVO, 1970 apud FIORENTINI e MIORIM, 1990, p. 4).

Assim, a realização das atividades com a utilização de materiais concretos é essencial no ensino-aprendizagem de matemática, pois auxilia os alunos na construção do conhecimento, tornando a aprendizagem mais fácil e significativa através de atividades significativas e contextualizadas (AUSUBEL, 1982). Nesse aspecto, o papel dos professores é o de elaborar atividades que envolvam experiências concretas proporcionando aos alunos o conhecimento necessário para que eles possam transitar entre os conhecimentos matemáticos concreto e abstrato. Então, Arce (2002) destaca que o educador Pestalozzi afirmava que a educação das crianças deveria começar pela percepção dos objetos concretos com a realização de ações concretas e experimentações, pois a transição do conhecimento concreto para o abstrato deve ocorrer de maneira natural e intuitiva. Contudo, Borges (1998) afirma que é importante que os professores saibam o momento certo de auxiliar os alunos a transferirem um conceito geométrico da linguagem concreta para a simbólica através de atividades que utilizem materiais manipulativos.

Nesse sentido, Piaget (1973, p. 16) destaca a importância dos professores nesse processo educacional ao afirmar que:

É óbvio que o professor enquanto organizador permanece indispensável no sentido de criar as situações e de arquitetar os projetos iniciais que introduzam os problemas significativos à criança. Em segundo lugar, ele é necessário para proporcionar contraexemplos que forcem a reflexão e a reconsideração das soluções rápidas. O que é desejado é que o professor deixe de ser um expositor satisfeito em transmitir soluções prontas; o seu papel deveria ser aquele de um mentor, estimulando a iniciativa e a pesquisa. 
De acordo com o National Council of Teachers of Mathematics (NCTM, 1991), os materiais concretos são muito úteis na prática pedagógica dos professores para o ensino- aprendizagem da matemática, principalmente no ensino de conteúdos geométricos. De acordo com essa perspectiva, os professores possuem mais facilidade para descrever as ações de aprendizagem com o emprego dos objetos concretos do que com a utilização de uma simbologia abstrata cujo significado ainda não foi apropriado pelos alunos. Essa tarefa permitirá que os professores adquiram um entendimento mais expressivo sobre o pensamento e o raciocínio matemático de seus alunos, estimulando-os a se engajarem com mais propriedade nas tarefas propostas em sala de aula, buscando, assim, a ampliação do conhecimento matemático proposto nas atividades curriculares (NCTM, 1994).

De acordo com o NCTM (1989), é importante que as crianças realizem várias experiências com objetos e imagens que possam favorecer o seu desenvolvimento sensório, espacial e motor. Concordando com esse ponto de vista, Morelatti e Souza (2006) argumentam sobre a possibilidade de contextualização dos conteúdos geométricos para que os alunos percebam e valorizem a presença de elementos geométricos na natureza e nas criações humanas. Assim, Borges (1998, p. 86) afirma que existe a necessidade de uma:

(...) aprendizagem geométrica [voltada] para o desenvolvimento da criança, uma vez que, várias situações escolares exigem dela percepção espacial tanto em Matemática como em leitura e escrita. A resolução de problemas aritméticos através da Geometria é um excelente meio para a criança indicar seu nível de compreensão, seus anseios e suas dificuldades. Problemas que os professores julgam que só podem ser resolvidos através de cálculos aritméticos são resolvidos pelas crianças através de desenhos.

Porém, para que essa abordagem pedagógica seja implantada e implementada, é preciso oferecer condições para que as crianças realizem explorações e investigações no ensino-aprendizagem da geometria, pois através dessas estratégias de ensino elas adquirem as ferramentas necessárias para sistematizar os conceitos geométricos (FIORENTINI, 2006). Então, as crianças necessitam visualizar, identificar, verificar e esboçar formas geométricas através de dobraduras, recortes, moldes, deformações, montagens, sombras e decomposições para, em seguida, desenhar e relatar o processo de aprendizagem dos conteúdos geométricos (NCTM, 1991).

Finalizando, as relações geométricas são extremamente importantes e úteis em situações encontradas no cotidiano, pois permitem que os alunos realizem conexões com 
outras áreas do conhecimento humano. Nessa perspectiva, entende-se que "a geometria nos ajuda a representar e descrever de forma organizada o mundo em que vivemos" (NCTM, 1991, p. 48). Diante dessa afirmativa, é de fundamental importância que as crianças construam as ideias e os conceitos geométricos através da utilização de materiais concretos para, depois, abstrair os seus conceitos, para um melhor entendimento do conteúdo matemático a ser abordado.

\section{METODOLOGIA}

Este trabalho caracteriza-se como uma pesquisa de natureza aplicada, aquela que, de acordo com Silva (2004), tem o objetivo de gerar conhecimentos práticos dirigidos à solução de problemas específicos. A abordagem deste estudo é qualitativa, ou seja, o ambiente natural serve como fonte direta para coleta de dados, sendo o pesquisador o instrumento chave (SILVA, 2004). Quantos aos objetivos, essa pesquisa é exploratória em virtude do levantamento bibliográfico realizado em função do referencial teórico exposto, além de ser explicativa ao identificar os fatores que determinam ou contribuem para a ocorrência dos fenômenos (SILVA, 2004). Os procedimentos técnicos adotados incluem pesquisas bibliográfica e documental, além de um estudo de caso baseado na experiência obtida em sala de aula, na escola onde este estudo foi aplicado, a partir da utilização de materiais concretos.

A esse respeito, cabe ressaltar que a investigação sobre a utilização de materiais concretos como recurso didático-pedagógico para as práticas de ensino-aprendizagem em matemática, com ênfase nos conteúdos geométricos, mostrou-se desafiadora. A partir de leituras de artigos, Trabalhos de Conclusão de Curso (TCC) e monografias, essa pesquisa teve como objetivo estudar e analisar as principais contribuições teóricas existentes sobre a utilização de material concreto no ensino-aprendizagem de geometria, para a ampliação do conhecimento geométrico dos alunos. Esse estudo também procurou desenvolver o dominínio do conhecimento geométrico do pesquisador sobre o tema proposto, para, posteriormente, utilizá-lo como instrumento auxiliar em trabalhos futuros.

Portanto, esse estudo investigou a eficácia da instrução ministrada com o auxílio de materiais concretos no ensino da geometria para alunos do $6^{\circ}$ ano do ensino fundamental, de uma escola particular no município de João Monlevade, no Estado de Minas Gerais. Assim, foram utilizados materiais concretos variados, como, por exemplo, folha de papel sulfite A4, palitos de churrasco e picolé, canudinhos, lixas e outros 
materiais manipulativos. Então, através desse estudo, pretendeu-se verificar se o trabalho com o material concreto auxilia os alunos a:

a) Ampliarem o interesse pelas aulas de geometria.

b) Identificarem e distinguirem as figuras geométricas.

O objetivo geral desse projeto foi o de desvendar, juntamente com os alunos, a importância da utilização do material concreto no estudo da geometria como mediador na construção do conhecimento geométrico, primeiramente, através do modo prático e, em seguida, através da generalização dos conceitos que foram ensinados aos alunos. Por outro lado, os objetivos específicos foram o de capacitar os alunos para identificar as diferentes figuras geométricas e desenvolver a aptidão de trabalho em grupo e individual através do método da descoberta com a utilização dos materiais concretos nas atividades propostas.

\subsection{Justificativa}

Os professores sentem-se felizes e ao mesmo tempo realizados ao perceberem que seus alunos estão conseguindo ampliar o conhecimento matemático através das atividades curriculares propostas. Portanto, os professores sentem-se recompensados quando a aprendizagem pode ser considerada como o produto da utilização de uma instrução diferenciada, que depende de seu esforço para realizar uma prática pedagógica que atenda às necessidades de seus alunos. Na maioria das vezes, os professores se preocupam, somente, em cumprir o programa curricular tornando as aulas uma sucessão de perguntas e respostas, onde quem pergunta sempre são os alunos e quem responde são sempre os professores.

Por outro lado, a geometria é um conteúdo que, na maioria das vezes, é relegado a segundo plano no ensino da matemática (LORENZATO; VILA, 1993), pois a maioria dos professores alega que não existe tempo suficiente para ministrá-la. Assim, quando os professores ministram essa disciplina, as aulas são compostas por um conjunto de normas e fórmulas que são resolvidas com perguntas e respostas para que os alunos somente memorizem o conteúdo ensinado, sem se apropriarem com o significado e nem com o sentido dos conceitos geométricos que foram abordados.

Dessa maneira, a condução desse estudo justifica-se pela necessidade de se abraçar novas técnicas pedagógicas, como, por exemplo, o material concreto, para apresentá-las aos professores, como sendo uma ferramenta importante para o ensino- 
aprendizagem da matemática, visando a utilização de outras maneiras pedagógicas para se inovar o ensino da geometria no currículo escolar.

\subsection{Duração do Projeto}

O projeto teve inicio em abril e terminou em setembro de 2011. Essa intervenção pedagógica foi realizada com os alunos da turma do $6^{\circ}$ ano do ensino fundamental através da utilização de uma aula de geometria por semana com duração de 50 minutos.

\subsection{Caracterização dos Alunos}

A turma de $6^{\circ}$ ano era composta por 17 alunos, sendo 12 meninos e 5 meninas. A idade desses alunos variava entre 11 e 12 anos. A maioria dos alunos possuía uma boa condição financeira, sendo que apenas alguns deles necessitam de bolsa de estudos. Quanto à aprendizagem em matemática, observou-se certo desinteresse pelos alunos, desde quando a professora começou a lecionar matemática, nessa escola, em abril de 2011. Por esse motivo, foi proposto à coordenação pedagógica o desenvolvimento de um projeto de intervenção que fosse composto por aulas que tivessem um ritmo de estudo diferenciado daquele, anteriormente, vivenciado pelos alunos.

\subsection{Procedimentos Metodológicos}

Como estratégia de ensino-aprendizagem para as aulas de geometria, a professora utilizou uma exposição de slides em PowerPoint, onde foram expostos conceitos geométricos a serem trabalhados ao longo do projeto. Os slides possuíam uma parte teórica e outra ilustrativa. Por exemplo, a parte ilustrativa apresentava um tripé no qual a abertura de seus pés formavam ângulos. Assim, pôde-se explicar e exemplificar o conteúdo geométrico referente a ângulos para os alunos do $6^{\circ}$ ano.

$\mathrm{Na}$ semana seguinte, foram realizados trabalhos com a utilização de material concreto, como, por exemplo, um botão de camisa para representar um ponto em um plano. Nesse caso, o plano era o caderno e o ponto era o botão. Em outro exemplo, para o trabalho com segmentos de retas em um plano, os alunos utilizaram o caderno como sendo o plano e o canudinho para representar o segmento de reta. Depois, nomearam o ponto A e o ponto B nas extremidades do canudinho, identificando, dessa maneira, um segmento de reta. Assim, foram trabalhados vários conceitos geométricos com a utilização de diversos tipos de material concreto, como palitos de churrasco, canudinhos, barbante, botões de camisa e caixas de isopor. 


\subsubsection{Atividade 1: Ponto, Reta e Plano}

O principal objetivo dessa atividade foi o de entender que, em um plano, existem infinitas retas que passam por um único ponto. Primeiramente, os alunos tiveram um aporte teórico e, em seguida, foi solicitado que eles trabalhassem com o material concreto disponibilizado para essa atividade.

Figura 1: Trabalho mostrando o plano, um ponto e retas

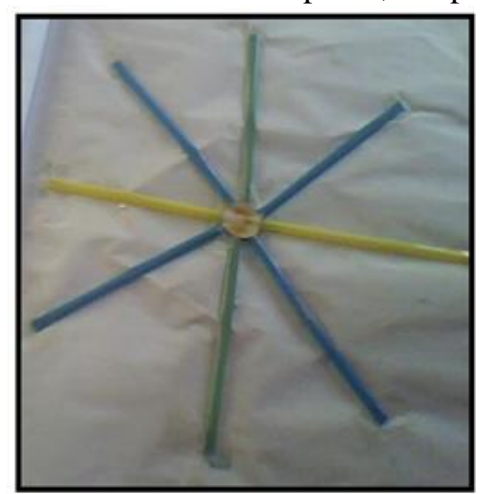

Fonte: Pesquisa aplicada (2011)

\subsubsection{Atividade 2: Polígonos Convexos e Não-convexos}

O principal objetivo dessa atividade foi introduzir os conceitos de polígono convexo e não-convexo. Primeiramente, esses conceitos foram trabalhados com o auxílio do livro e, em seguida, os alunos discutiram esses conceitos e participaram da atividade proposta com o auxílio de material concreto.

Assim, os alunos utilizaram pedaços de arame e, com dobraduras, construíram os polígonos não-convexos.

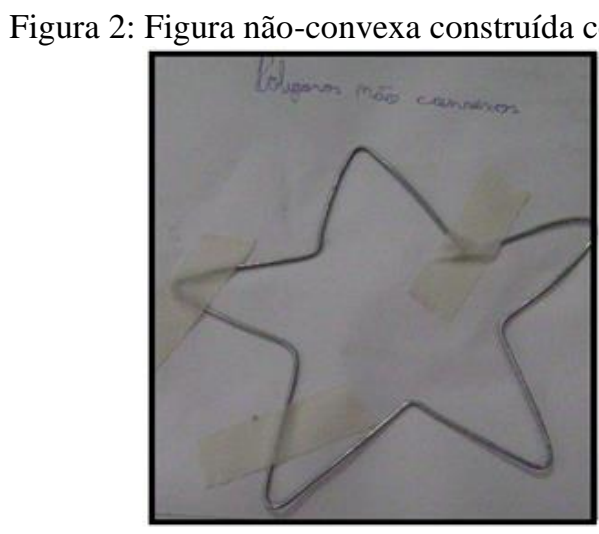

Fonte: Pesquisa aplicada (2011)

Os polígonos convexos foram construídos com a utilização de canudinhos. 
Figura 3: Figura convexa construída com canudinho

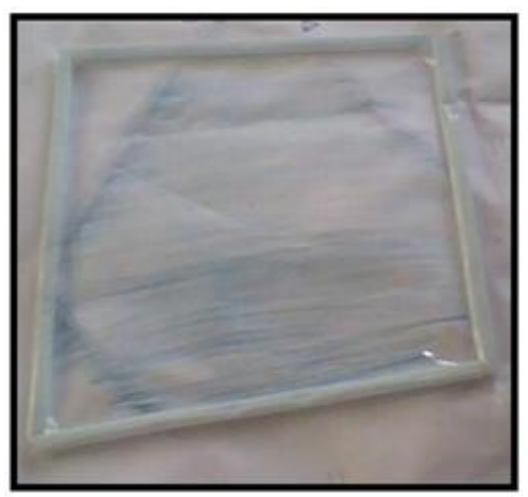

Fonte: Pesquisa aplicada (2011)

\subsubsection{Atividade 3: Triângulos e Quadriláteros}

O principal objetivo dessa atividade foi mostrar os diversos tipos de triângulos e quadriláteros e, também, a sua conceituação e propriedades. Assim, o livro foi utilizado para que os alunos pudessem verificar os conceitos de triângulo e quadrilátero e, também, a definição e as propriedades desses polígonos.

Posteriormente, foi solicitado que os alunos, em grupos, construíssem os triângulos considerando a propriedade de cada um deles. Por exemplo, um grupo de alunos trabalhou com um triângulo escaleno e utilizou o material concreto para construilo sobre o desenho que foi realizado anteriormente. Depois, explicaram aos outros grupos de alunos as propriedades principais desse tipo de triângulo. Essa abordagem pedagógica foi utilizada com os outros grupos para o trabalho com os demais tipos de triângulos.

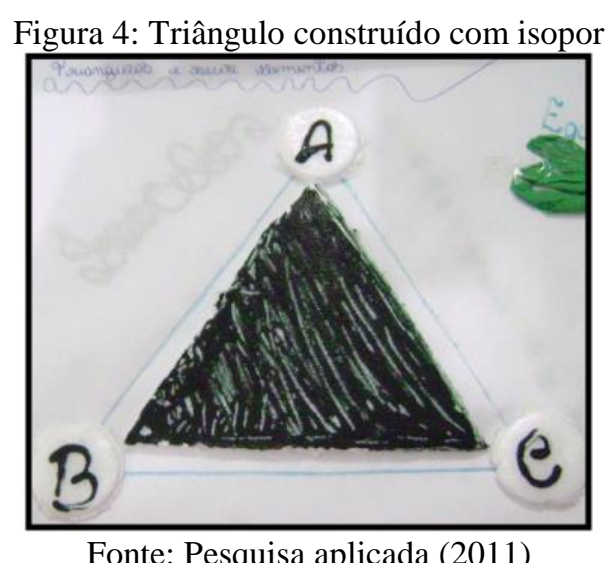

Quanto aos quadriláteros, os grupos de alunos escolheram um deles e o desenharam no plano de acordo com a sua criatividade e com o material concreto disponível. 
Figura 5: Quadrilátero construído com canudinhos

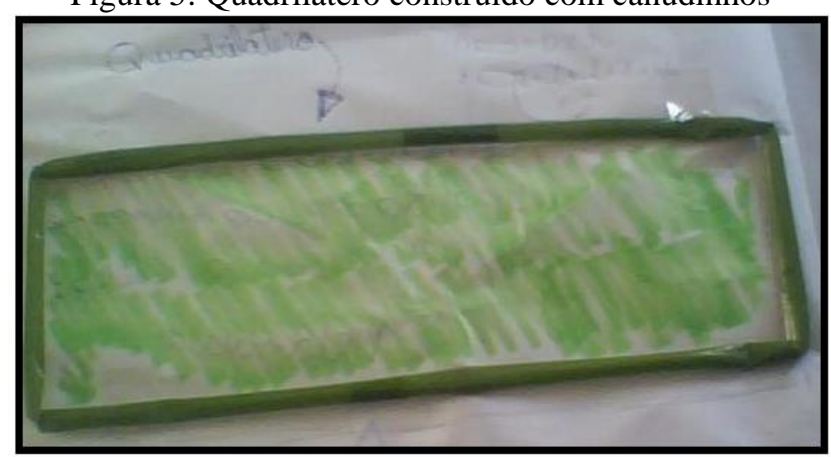

Fonte: Pesquisa aplicada (2011)

Para a realização dessas atividades, os alunos trabalharam em grupos de 3 ou 4 participantes, pois essa dinâmica facilitava o questionamento deles com relação às dúvidas que surgiam para a realização das atividades curriculares propostas. $\mathrm{O}$ trabalho em grupo teve como objetivo buscar a melhor maneira para a realização das tarefas com a participação colaborativa dos alunos nas atividades. A interferência da professora somente ocorreu nos momentos em que os alunos não conseguiam resolver uma determinada situação-problema relacionada com a geometria.

Nesse processo, a professora observava os alunos que não estavam conseguindo aprender o conteúdo proposto. Por exemplo, os alunos que tinham dificuldades na aprendizagem do conteúdo eram colocados em grupos para a realização de um trabalho diferenciado de intervenção. A professora verificava constantemente o progresso do aprendizado desses alunos, verificando se eles conseguiam relacionar a teoria com a prática desenvolvida nas atividades curriculares propostas.

\subsubsection{Trabalho Final}

No final dessa intervenção pedagógica, a professora solicitou aos alunos que, tendo em vista os conhecimentos adquiridos durante as aulas desse projeto, que em grupos, elaborassem um trabalho final envolvendo as figuras geométricas que foram trabalhadas durante a realização das atividades, utilizando, para isso, o material concreto com palitos, canudinhos, isopor, barbantes e outros. 
Figura 6: Exemplos de trabalho final elaborado pelos alunos

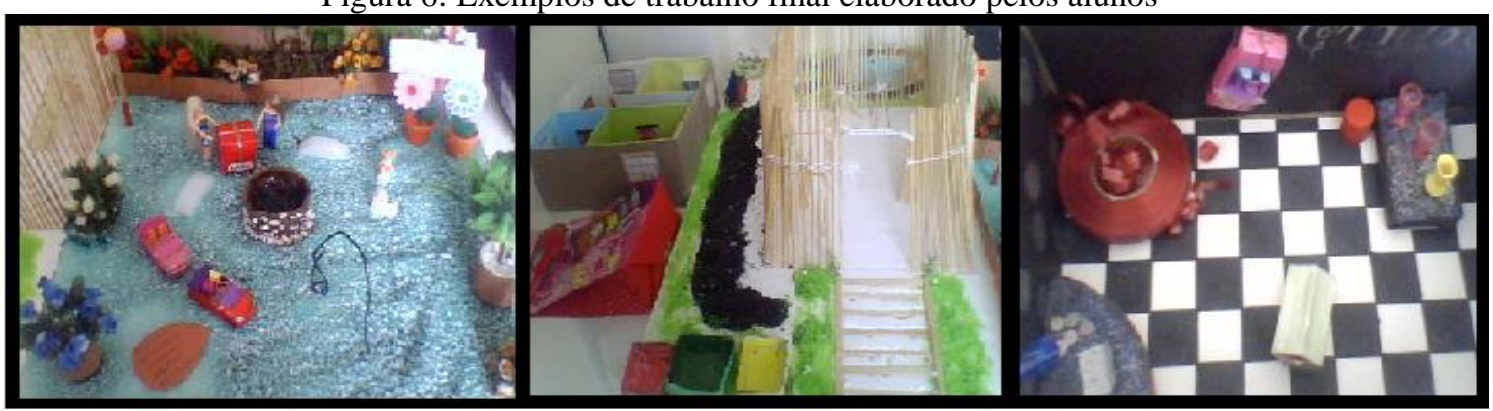

Fonte: Pesquisa aplicada (2011)

\subsubsection{Avaliação dos Alunos}

Durante a intervenção pedagógica, os alunos foram avaliados formativamente durante todo o processo de ensino-aprendizagem através da utilização do material concreto para a construção da figuras geométricas que foram propostas nas atividades realizadas durante as aulas.

\section{ANÁLISE E DISCUSSÃO DOS RESULTADOS}

Ao se trabalhar com o material concreto, os alunos apresentaram um maior interesse pelas aulas de matemática e, principalmente, pelo conteúdo de geometria. Nesse estudo, através das atividades realizadas, o trabalho com o material o concreto permitiu que os alunos fossem capazes de distinguir e identificar as figuras geométricas e as suas propriedades bem como identificar outros elementos geométricos como, por exemplo, o ponto, o plano, a reta e os segmentos de reta.

Desde o início, os alunos empolgaram-se com o projeto. Tanto que, nos dias próximos às avaliações bimestrais de todas as disciplinas, era necessária a utilização das aulas de geometria para discutir alguns conceitos algébricos para a realização da avaliação de matemática. Os alunos não gostaram desse procedimento e queriam que as aulas de geometria fossem ministradas, pois esse era o único momento para que eles expusessem as suas deduções e os conhecimentos que adquiriam durante o processo de intervenção pedagógica.

Verificou-se que os alunos aceitaram e aprovaram a utilização do material concreto no ensino-aprendizagem da geometria, que ocorreu de maneira significativa, favorecendo nos alunos a construção dos conceitos geométricos a serem estudados. Assim, considerando as atividades propostas, houve aprendizagem por parte dos alunos, 
pois eles conseguiram estabelecer relações entre os conceitos contidos nos livros e a sua aplicação nas atividades envolvendo a utilização do material concreto em atividades práticas. Por outro lado, alguns alunos não conseguiram compreender a relação entre a teoria e a atividade prática desenvolvida com os materiais concretos. Esses alunos foram colocados em grupos para a realização de um trabalho pedagógico diferenciado para atender às suas necessidades educacionais com relação ao conteúdo abordado.

A busca por mais informação a respeito dos conceitos geométricos trabalhados com os grupos, a organização dos alunos nos grupos, a interação, a criatividade, a exploração em busca de novas maneiras de se conceber os conceitos descritos foram observados no processo de avaliação formativa. Não houve uma avaliação escrita, porém, a professora observou todos os alunos em seus grupos durante a realização das atividades. Dessa maneira, a professora pôde verificar quais eram os alunos que tinham dificuldades em relacionar o conteúdo geométrico que foi trabalhado na teoria com aquele que estava sendo proposto na prática através da utilização do material concreto. Assim, a avaliação contínua permitiu que os alunos escrevessem um parágrafo relatando sobre a participação de cada um nas atividades realizadas durante as aulas de geometria.

De um modo geral, o desenvolvimento do projeto foi positivo, pois os alunos apresentaram um produto final envolvendo o trabalho com as figuras geométricas. Os trabalhos finais foram elaborados dentro do que era esperado, além de apresentarem conceitos geométricos aprendidos durante o projeto de intervenção pedagógica. A maioria dos alunos soube explicar exatamente o conteúdo geométrico apresentado no trabalho, como, por exemplo, a identificação das figuras geométricas utilizadas e as suas propriedades. Portanto, percebe-se que os alunos conseguiram adquirir um nível de conhecimento geométrico bastante significativo durante a realização das atividades. A exibição dos trabalhos finais na escola permitiu que os alunos socializassem o resultado do projeto que desenvolveram.

A pesquisa bibliográfica realizada reforçou a importância de se trabalhar com uma metodologia que promovesse a auto-suficiência dos alunos. Assim, os resultados positivos adquiridos com as atividades propostas mostraram que a metodologia utilizada conseguiu promover a autonomia dos alunos, tornando-os ao mesmo tempo críticos e aptos para discutirem e questionarem sobre as idéias pertinentes aos conceitos geométricos trabalhados em sala de aula. Essa abordagem pedagógica também 
possibilitou que os alunos organizassem maneiras diferenciadas para enfrentar novas situações relacionadas com os conceitos geométricos que eram estudados.

Por outro lado, esse projeto de intervenção pedagógica proporcionou, aos alunos, oportunidades de trabalho em grupo que os auxiliaram na experimentação da construção de figuras geométricas. Assim, houve a promoção da construção do conhecimento geométrico, pois os alunos foram capazes de encontrar a solução para os problemas propostos, uma vez que investigar significa experimentar. Assim, ao se desenvolver atividades experimentais com a utilização de material concreto, verificou-se que os alunos obtiveram sucesso no aprendizado dos conceitos geométricos que foram propostos. $\mathrm{O}$ sucesso da aprendizagem em geometria foi verificado em todo o processo de intervenção pedagógica, pois a professora selecionou um tipo de material concreto específico para cada tipo de atividade trabalhada em sala de aula.

\section{CONSIDERAÇÕES FINAIS}

O principal objetivo desse artigo foi propor que o ensino da matemática seja possibilitado através de uma aprendizagem significativa e contextualizada para os alunos. Assim, procurou-se, através de aulas diferenciadas, propor atividades para o ensino da geometria mostrando a importância da utilização de materiais concretos, pois esses materiais favorecem o entendimento e a aplicação prática dos conceitos geométricos na construção de conhecimento matemático trabalhado em sala de aula. Para isso, várias atividades foram realizadas e a prática mostrou que o papel do professor de matemática precisa ir além da exposição de conteúdo descontextualizado para a simples memorização. É preciso lançar mão de técnicas que aproximem os alunos da realidade e os façam entender o que está em volta.

Dessa forma, a utilização de materiais concretos no ensino-aprendizagem da geometria auxilia os alunos através da visualização dos conceitos geométricos a aprender, a compreender, a entender e a fixar conceitos importantes de geometria. Essa abordagem favoreceu, dessa maneira, a motivação e o interesse dos alunos no processo de ensinoaprendizagem em geometria, no qual o material concreto contribuiu para que os alunos criassem sua própria forma de entendimento.

É possível concluir, então, que a realização do projeto aqui relatado possibilitou uma melhor avaliação dos alunos em relação ao seu conhecimento geométrico, pois 
permitiu que os estudantes trabalhassem a geometria de uma maneira lúdica e objetiva, conduzindo-os à observação, à experimentação e à construção do conhecimento.

Esse estudo não esgota o assunto abordado. Pelo contrário, ele reforça a necessidade de novas experimentações pedagógicas relacionadas ao ensino de Matemática. Outros estudos semelhantes e mais aprofundados, sobretudo interdisciplinares, podem e devem ser executados por educadores, uma vez que a busca pela excelência no ensino deve ser uma constante para todo e qualquer professor.

\section{REFERÊNCIAS}

ARCE, A. A pedagogia na "era das revoluções": uma análise do pensamento de Pestalozzi e Froebel. Campinas, SP: Autores Associados, 2002.

AUSUBEL, D. P. A aprendizagem significativa: a teoria de David Ausubel. São Paulo, SP: Moraes, 1982.

BORGES, G. C. M. Noções de geometria descritiva: teoria e exercício. Porto Alegre, RS: Sagra-Luzzatto, 1998.

BRASIL. Parâmetros curriculares nacionais de matemática - PCNs. Brasília, DF: MEC/SEF, 1997.

CASTELNUOVO, E. Didática de la matemática moderna. México, DF: Trillas, 1970.

CHIE, M. T.; GLASER, R. (1980). The measurement of expertise: analysis of the development of knowledge and skill as a basis for assessing achievement. In BAKER, E. L.;

DANTAS, L. E.; MANOEL, E. J. (2005). Conhecimento no desempenho de habilidades motoras: o problema do especialista motor. In Tani, G. (Ed.). Comportamento motor: aprendizagem e desenvolvimento. Rio de Janeiro, RJ: Guanabara Koogan, 2005. p. 295313.

DIENES, Z. G. A Matemática moderna no ensino primário. São Paulo, SP. Editora Fundo de

Cultura S/A, 1967.

FIORENTINI, D.; MIORIM, M. A. Uma reflexão sobre o uso dos materiais concretos e jogos no ensino da matemática. BOLEMA, n.7, p. 5-10, 1990.

FIORENTINI, D. Grupo de sábado: uma história de reflexão, investigação e escrita sobre a prática escolar em matemática. In: FIORENTINI, D.; CRISTÓVÃO, E. M. (Org.). 
Histórias e investigação delem aulas de matemática. Campinas, SP: Editora Alínea, 2006. p. 13-36.

LORENZATO, S.; VILA, M. C. Século XXI: qual matemática é recomendável? Zetetiké, v. 1, n. 1, p. 41-49, 1993.

MORELATTI, M. R. M.; SOUZA L. H. G., Aprendizagem de conceitos geométricos pelo futuro professor das séries iniciais do Ensino Fundamental e as novas tecnologias. Curitiba, PR: UFPR, 2006.

NCTM. Curriculum and evaluation standards for school mathematics. Reston, Va.: NCTM, 1989.

NCTM (1991). Normas para o currículo e a avaliação em matemática escolar. Lisboa, Portugal: APM e IIE.

NCTM (1994). Normas profissionais para o ensino da matemática. Lisboa, Portugal: APM e IIE.

PAIS, L. C. Ensinar e aprender matemática. São Paulo, SP: Autêntica, 2006.

PEREZ, G. A realidade sobre o ensino da geometria no 1o. e 2o. graus, no Estado de São Paulo. A Educação Matemática em Revista, n. 4, p. 54-62, 1995.

PIAGET, J. Estudos sociológicos. Rio de Janeiro, RJ: Forense, 1973.

SILVA, Cassandra Ribeiro de Oliveira e. Guia Prático de Metodologia e Organização do projeto de pesquisa. Documento do Centro de Ensino Técnico Federal (Cefet), publicado em 2004. 